\title{
Local Illumination Influence on Vegetation Indices and Plant Area Index (PAI) Relationships
}

\section{Flávio Jorge Ponzoni ${ }^{1}{ }^{*}$, Clayton Borges da Silva ${ }^{1}$, Sandra Benfica dos Santos ${ }^{1}$, Otávio Cristiano Montanher ${ }^{2}$ and Thiago Batista dos Santos ${ }^{1}$}

1 Instituto Nacional de Pesquisas Espaciais, Avenida dos Astronautas, 1758, São José dos Campos 12227, Brazil; E-Mails: clayton@dsr.inpe.br (C.B.S.); sandra@dsr.inpe.br (S.B.S.); batista@dsr.inpe.br (T.B.S.)

2 Departamento de Tecnologia, Universidade Estadual de Maringá, Avenida Colombo, 5790, Jd. Universitário, Maringá 87020, Brazil; E-Mail: ocmontanher2@uem.br

* Author to whom correspondence should be addressed; E-Mail: flavio@dsr.inpe.br; Tel.: +55-12-3208-6454; Fax: +55-12-3208-6488.

Received: 19 March 2014; in revised form: 24 June 2014 / Accepted: 25 June 2014 /

Published: 3 July 2014

\begin{abstract}
Relationships between biophysical parameters and radiometric data have been tested and evaluated by several professionals using empirical and/or physical approaches. Remote sensing data collected from airborne or orbital platforms are, of course, influenced by different factors, such as illumination/observation geometry (data collection geometry), atmospheric effects, etc., rather than by target spectral properties. Besides that, the target topographic positioning actually defines the amount of incident energy, as well as the amount of energy that is reflected toward the sensor. The sum of both data collection geometry and topographic positioning defines the so-called "local illumination". The objective of this paper was to evaluate the influence of local illumination on empirical relationships between a biophysical variable (plant area index, PAI) and two vegetation indices calculated from Resourcesat/Linear Imaging Self-Scanner sensor (LISS-3) orbital data. Local illumination was expressed by the cosine factor (Fcos) and calculated from topographic and solar position data at three different dates. The study area was based on a typical Brazilian southeastern forest fragment located in the Augusto Ruschi municipal preservation park dispersed on roughhouse topography. PAI was estimated by hemispherical photographs taken under the forest canopy from sample points arbitrarily dispersed on the forest fragment. Results confirmed a stronger relationship between vegetation indices and local illumination conditions.
\end{abstract}


Keywords: NDVI; NDMI; biophysical parameters; remote sensing data acquisition

\section{Introduction}

Remote sensing technology has been applied to vegetation studies, including biophysical parameters estimation, such as above ground biomass (AGB), water and chlorophyll leaf content, leaf area index (LAI), etc. [1]. Such estimation can be performed by empirical or physical approaches [2], but several of them include radiometric data extracted from airborne or orbital sensor images, which can include transformations, such as vegetation indices.

Independent of the adopted approach (empirical or physical), radiometric orbital data are frequently converted to surface reflectance before the modeling definition or the vegetation index calculation. It is influenced by several aspects, including illumination/observation geometry, since vegetation presents anisotropic behavior [3]. Here, such geometry is called "data acquisition geometry".

The influence of data acquisition geometry on the surface reflectance from vegetation cover has been reported by several authors, such as [4-8], but its effects become more complex when the vegetation cover under study is spread out on severe topographic conditions. In such cases, there is an additional influence on the surface reflectance that will be treated here as "local illumination".

Sun positioning and sensor observation angle define the data acquisition geometry, which, in turn, defines the local illumination for each pixel according to its topographic location. Therefore, the amount of reflected radiation from each pixel is dependent on these two factors that influence not only the radiometric data themselves, but also their radiometric transformations, such as the vegetation indices. As a consequence of such influence, the empirical relationships between vegetation biophysical parameters and radiometric orbital data become weak or sometimes can express a false and strong relationship.

The influence of local illumination is frequently neglected by several researchers and ordinary remote sensing data users, and also frequent empirical relationships between orbital radiometric data and biophysical parameters from different vegetation types have been assumed as stable and uniform, independent of the data set (sensor characteristics and acquisition geometry). Of course, such an influence is more or less expected depending on the data set characteristics, such as spatial resolution. Developing any kind of modeling approach involving a radiometric and vegetation biophysical data relationship must take into account how the interaction process between electromagnetic radiation and vegetation has been translated by the sensor data set. There are several possible translations for the same phenomenon.

One of the most important vegetation biophysical parameters utilized on vegetation studies and carried out by remote sensing technology is LAI [2]. Empirical relationships between vegetation indices and LAI have been proposed by [9-14], but these authors and several others have described their results for specific local illumination conditions, and little local topographic information has been provided. It is possible that different results could be achieved when working with different data sets.

Estimating LAI from indirect methods (nondestructive) based on radioactive transfer modeling and from forests will be treated here as PAI, since more than leaves are considered on the radiation 
trajectory inside the vegetation canopy during LAI estimation from hemispherical photography. Similar terminology has been adopted by [15-17]. Some authors, like [18], have preferred using vegetation area index (VAI).

The objective of this paper is to evaluate the influence of local illumination on the empirical relationships between PAI estimated from a tropical rain forest fragment and vegetation indices calculated from Resourcesat/Linear Imaging Self-Scanner sensor (LISS-3) data.

\section{Methodology}

\subsection{Study Area}

There is a relatively well-preserved forest fragment covering almost the entire 245 ha area of the Augusto Ruschi Municipal Park located near the town of São José dos Campos, State of São Paulo, Brazil. This forest fragment presents different succession stages of a typical southeastern coast Brazilian rain forest. Its relief is characterized by a slightly roughhouse landscape with altitudes ranging from 600 to $900 \mathrm{~m}$ above sea level.

Figure 1. Study area location in a regional context and a Resourcesat/ Linear Imaging Self-Scanner sensor (LISS-3) image showing the forest fragment (in reddish color).
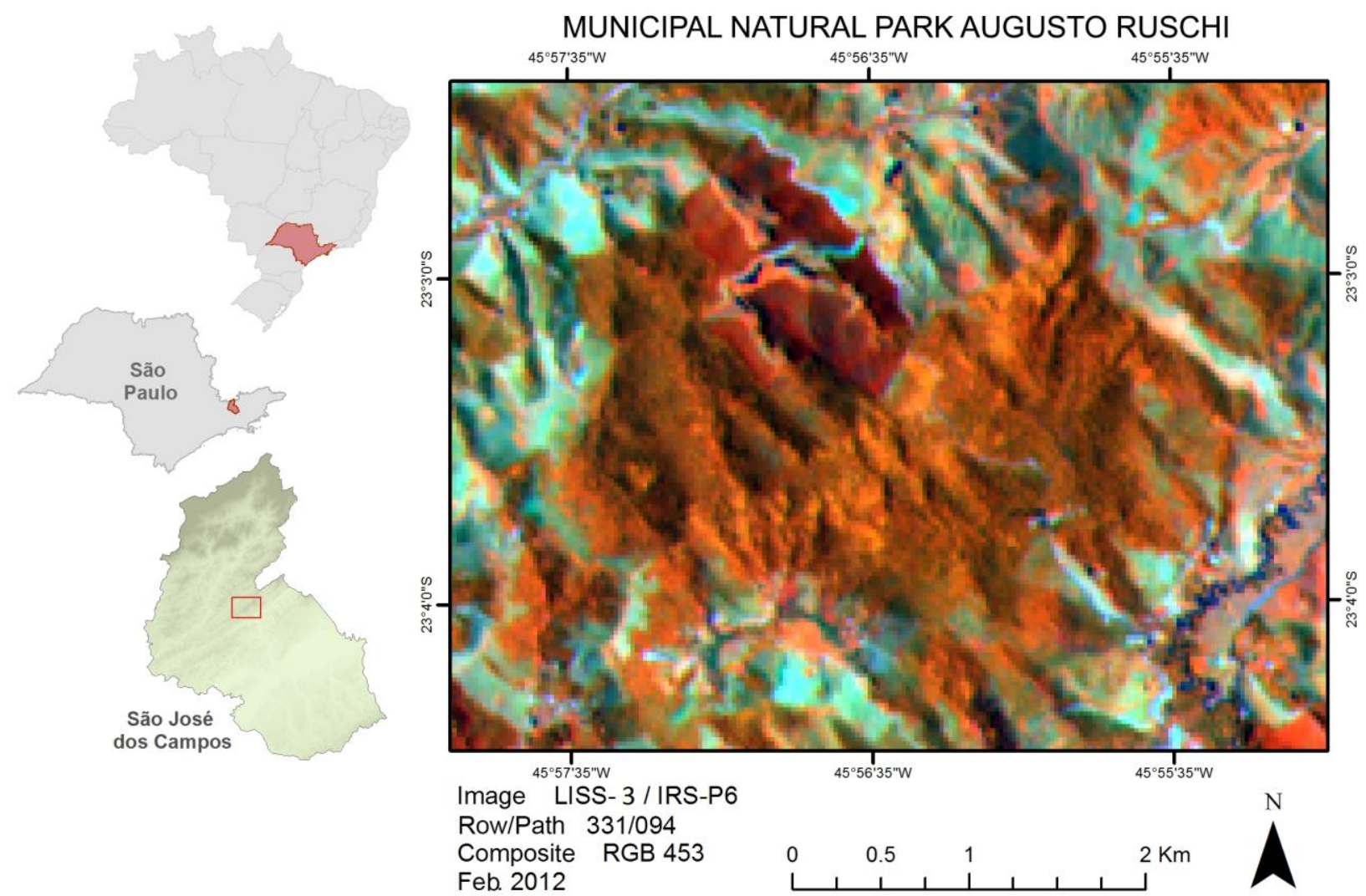

The regional weather presents two annual climate seasons relatively well defined and characterized by differences of precipitation levels rather than by temperatures. The highest precipitation levels are reached from November to March (around $1250 \mathrm{~mm}$ ), while the driest period occurs from June to August (around $50 \mathrm{~mm}$ ). The temperature changes according to the precipitation cycle, which is 
around $20{ }^{\circ} \mathrm{C}$ in June and $31{ }^{\circ} \mathrm{C}$ in January [19]. Figure 1 shows the location of the study area in a regional context.

In spite of being located in a region characterized by variations according to precipitation and temperature levels, the forest fragment presents low phenological variations. Studies developed in forest fragments located near the town of São José dos Campos, such as those developed by [20,21], have demonstrated that LAI or PAI variation is strongly dependent on the species composition. The authors concluded that evergreen forest fragments occur more frequently near the coast border where the driest season is short and weak, and there are high levels of evergreen species (around 87\%) composing the forest canopies [22]. The farther forest fragments are from the coast, the more the non-evergreen species increase [23].

The forest fragment under study is located around $80 \mathrm{~km}$ from the coast; thus, few variations on PAI have been expected, due to the season variation.

\subsection{Resourcesat/LISS-3 Images}

The Resourcesat/LISS-3 is an Indian satellite/sensor, whose images have also been freely distributed in Brazil. The main Linear Imaging Self-Scanner sensor (LISS-3) characteristics are presented in Table 1.

Table 1. Resourcesat/LISS-3 main characteristics.

\begin{tabular}{cccccc}
\hline $\begin{array}{c}\text { Spectral } \\
\text { Bands }\end{array}$ & $\begin{array}{c}\text { Spectral } \\
\text { Range } \\
(\boldsymbol{\mu m})\end{array}$ & $\begin{array}{c}\text { Spatial } \\
\text { Resolution }(\mathbf{m})\end{array}$ & $\begin{array}{c}\text { Temporal Resolution } \\
(\mathbf{d a y s})\end{array}$ & $\begin{array}{c}\text { Swath } \\
(\mathbf{k m})\end{array}$ & $\begin{array}{c}\text { Radiometric } \\
\text { Resolution (bit) }\end{array}$ \\
\hline B1 & $0.52-0.59$ & 23.5 & 24 & 141 & 8 \\
B2 & $0.62-0.68$ & 23.5 & 24 & 141 & 8 \\
B3 & $0.77-0.86$ & 23.5 & 24 & 141 & 8 \\
B4 & $1.55-1.70$ & 23.5 & 24 & 141 & 8 \\
\hline
\end{tabular}

The Resourcesat/LISS-3 images were downloaded from the Instituto Nacional de Pesquisas Espaciais (INPE) website (path 331 row 94) and georeferenced using Geocover (TM/Landsat 5) images as the reference (datum WGS 84) with a spatial resolution of $14.5 \mathrm{~m}$.

The image digital numbers (DN) were converted to radiance and to TOA (top of atmosphere) reflectance using Equations (1) and (2) presented by [24]. The calibration coefficients utilized in these equations have been provided by the Resourcesat documentation also available on INPE's website.

$$
L_{\lambda}=\left(\frac{L \max _{\lambda}-L \min _{\lambda}}{D N \max _{\lambda}}\right) D N \max +L \min _{\lambda}
$$

where: $L_{\lambda}=$ TOA radiance at $\lambda$ (in $\mathrm{mW} / \mathrm{m}^{2} / \mathrm{Sr} / \mu \mathrm{m}$ ); $L_{\max _{\lambda}}=$ sensor maximum radiance at $\lambda$ (in $\mathrm{mW} / \mathrm{m}^{2} / \mathrm{Sr} / \mu \mathrm{m}$ ); $L_{\min _{\lambda}}=$ minimum radiance at $\lambda$ (in $\mathrm{mW} / \mathrm{m}^{2} / \mathrm{Sr} / \mu \mathrm{m}$ ); $D N_{\max _{\lambda}}=$ maximum digital number at $\lambda\left(2^{\mathrm{n}}\right)$;

$$
\rho_{\lambda}=\frac{\pi L_{\lambda} \cdot d^{2}}{\operatorname{Esun}_{\lambda} \cdot \cos \theta_{s}}
$$


where: $\rho_{\lambda}=$ TOA reflectance at $\lambda(\%) ; L_{\lambda}=$ TOA radiance at $\lambda\left(\mathrm{mW} / \mathrm{m}^{2} / \mathrm{sr} / \mu \mathrm{m}\right) ; \mathrm{d}=$ Earth-Sun distance (astronomic unity); $\theta_{S}=$ Sun elevation (degrees); $E_{\text {sun }_{\lambda}}=$ TOA solar irradiance at $\lambda\left(\mathrm{mW} / \mathrm{m}^{2} / \mu \mathrm{m}\right)$.

Table 2 ([25]) shows additional data of the Resourcesat/LISS-3 images utilized, including acquisition time and solar positioning.

Table 2. Resourcesat/LISS-3 data and solar positioning at the image acquisition dates.

\begin{tabular}{ccccccc}
\hline Acquisition & Time GMT & DOY & Earth/Sun Distance & Elevation & Zenith Cosine & Azimuth \\
\hline 8 February 2012 & $1: 07 \mathrm{pm}$ & 39 & 0.98662 & 58.08 & 0.8488 & 81.53 \\
1 July 2012 & $1: 08 \mathrm{pm}$ & 182 & 1.01667 & 35.51 & 0.5809 & 34.39 \\
5 October 2012 & $1: 12 \mathrm{pm}$ & 279 & 0.99976 & 59.86 & 0.8648 & 57.19 \\
\cline { 1 - 1 } & \multicolumn{7}{c}{ From: [25]. } \\
\hline \multicolumn{7}{c}{}
\end{tabular}

After the conversion to TOA reflectance, the images were submitted to the 6S (Second Simulation of a Satellite Signal in the Solar Spectrum) atmospheric correction code [26]. The adopted atmospheric model was tropical, and the aerosol was continental, with $50 \mathrm{~km}$ of visual visibility for February and July images and $35 \mathrm{~km}$ for October images. These visibility values were estimated taking into account historical atmospheric information provided by INPE's meteorological website. Based on that information, it was possible to realize that in February and in July the atmospheric conditions were favorable for satellite imagery, but worse in October. Therefore, $6 \mathrm{~S}$ code was run using different visibility values. The resulting reflectance surface data (images) were plotted in order to spectrally characterize known targets, such as vegetation (different cover types), water bodies and bare soils. The agreement between the expected surface reflectance curve shapes from these different targets and the $6 \mathrm{~S}$ resulting surface reflectance data were considered in the visibility value definition. The input average altitude was $600 \mathrm{~m}$ for the three Resourcesat/LISS-3 images.

The resulting images were assumed to be composed of surface reflectance values that were utilized as the basis for the vegetation indices calculation, which were correlated to PAI values estimated from the hemispherical photography. An important assumption was that the $6 \mathrm{~S}$ code would take as input data TOA reflectance values influenced by the local illumination condition (obviously dependent on the Sun positioning and topographic conditions). Therefore, the resulting surface reflectance values would also be dependent on it.

\subsection{Weather Conditions in the Study Area during Data Collection Campaigns}

The data collection was performed during two climate seasons of 2012, whose rainy period was quite long compared to that of previous years, starting in November of 2011 until June 2012. The historical average precipitation in June in São José dos Campos is around $50 \mathrm{~mm}$, but in 2012, it reached $121 \mathrm{~mm}$. Therefore, the driest season started in August and September, when the recorded precipitation was 10 and $13 \mathrm{~mm}$, respectively. Temperatures were also different compared to the historical average values of the same time period, which are around $30{ }^{\circ} \mathrm{C}$ in July and $17{ }^{\circ} \mathrm{C}$ and $19{ }^{\circ} \mathrm{C}$ in August and September, respectively.

Combining both phenological and local illumination changes, variation on orbital radiometric data was expected, leading to variations on biophysical $\times$ radiometric data relationships. 
Three field data collection campaigns were performed during 2012 in an attempt to explore phenological and local illumination changes. The first one was carried out at the end of the rainy season, between 25 March and 3 April 2012. The Resourcesat/LISS-3 images related to this season and period were from February with a Sun elevation of $58^{\circ}$. During this first field campaign, canopy structural data were also collected from transects of $10 \times 20 \mathrm{~m}$ (one per sample point). The positioning of each tree inside the transect was recorded. Data, such as diameter at breast height (DBH), total height $(\mathrm{H})$, commercial height $(\mathrm{CH})$, canopy horizontal projection (CHP), timber quality (TQ), canopy type (CT) and sociological positioning (SP) were also recorded from each measured tree. Canopy vertical profiles were drawn in order to visually analyze the vertical canopy structure. Here, we assumed that there were no significant canopy structural changes from February to October. Actually, phenological variations were expected during this period of time mainly characterized by LAI. As we used hemispherical photography, here we adopted PAI as a more appropriate term.

The second field data collection was performed between 26 June and 3 July considered here as an intermediate period between the rainy and the dry season. The Resourcesat/LISS-3 images from this period were generated on 1 July with a Sun elevation of $35.5^{\circ}$. The third and last field campaign was conducted between 24 September and 2 October here considered as the end of the dry season. The Resourcesat/LISS-3 images related to this period were generated on October 5.

In spite of having performed the first field campaign in April, here, we will label it according to the Resourcesat/LISS-3 imagery, whose first set of images was related to February.

\subsection{Sample Points Definition}

Taking the Resourcesat/LISS-3 image dates as references and topographic data from the study area at a $20 \mathrm{~m}$ spatial resolution, the cosine factor (Fcos) was calculated for each pixel for the different dates.

The Fcos is based on data from a digital terrain model (DTM) developed by [27] with a spatial resolution of $30 \mathrm{~m}$. Equation (3) represents the Fcos calculation.

$$
F \cos =\sqrt{\left(\left(\cos \left(\varphi_{x, y}-\varphi_{s}\right)+\left(\cos \left(\theta_{x, y}-\theta_{s}\right)\right)^{2}\right.\right.}
$$

where $\varphi_{x, y}$ is the pixel aspect, $\varphi_{s}$ is the solar azimuth at the image acquisition time, $\theta_{x, y}$ is the pixel slope and $\theta_{s}$ is the solar zenith at the image acquisition time.

Equation (3) was applied considering the three field campaign dates, resulting in three Fcos images, whose digital number represented amounts of electromagnetic radiation received by each pixel in each image acquisition time. Fcos values were ranged in illumination classes according to the Sun positioning for each image date. Three illumination classes were defined arbitrarily: low illumination (Fcos less than 0.4), illuminated (Fcos from 0.4 to 0.6) and high illumination (Fcos higher than 0.6). Figure 2 shows the spatial location of the sample points and the illumination simulation based on the DTM developed by [27] for each of the three Resourcesat/LISS-3 image dates.

On the right side of Figure 2, we included the Sun positioning and a simulation of the shadow direction just to give an idea of the expected changes on the ground illumination/shadowing. 
Figure 2. Sample points' positioning in the study area and the illumination simulation for the Resourcesat/LISS-3 image dates.

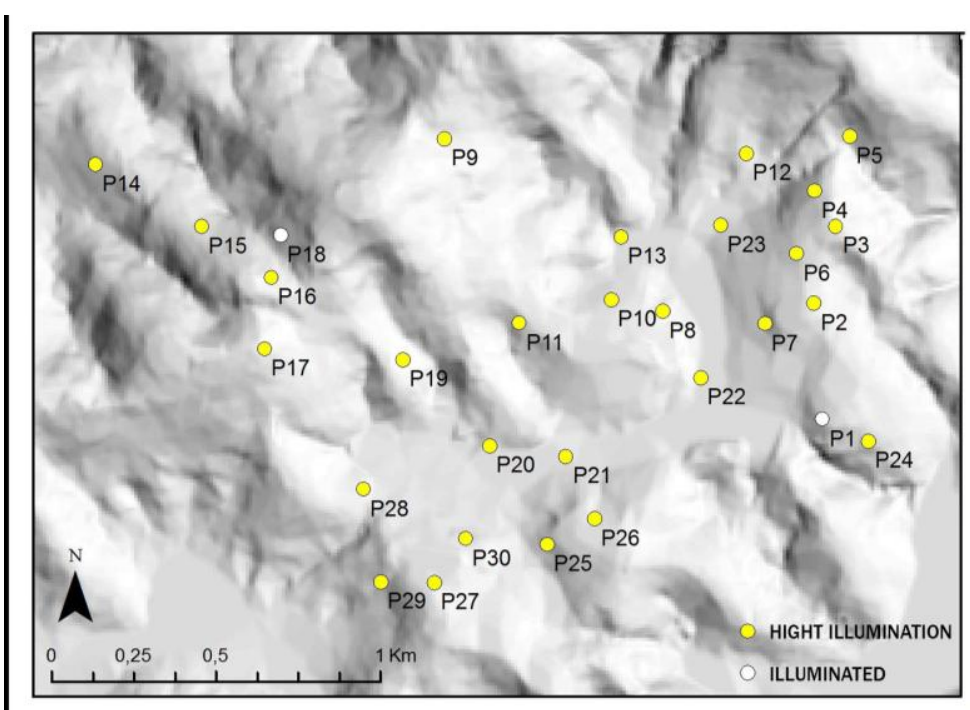

\section{FEBRUARY}
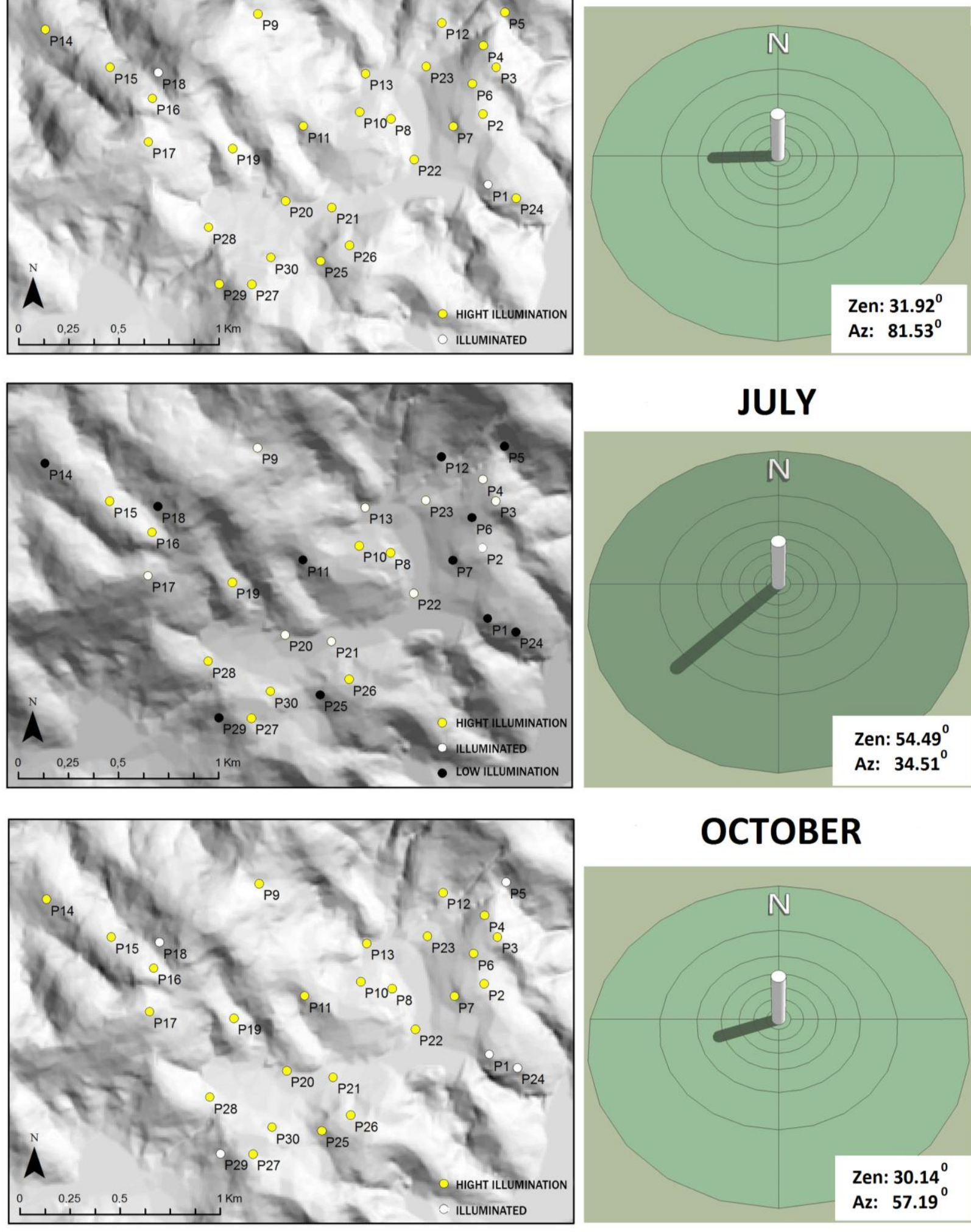

\section{OCTOBER}

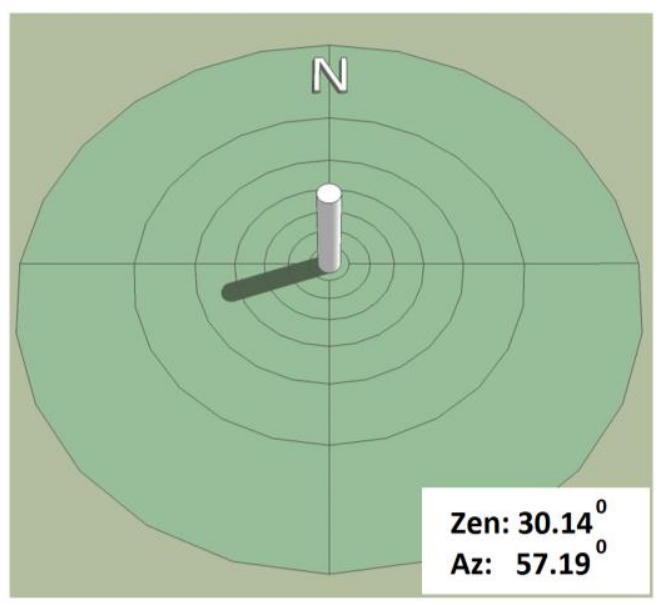

Note in Figure 3 that only in July did three illumination classes occur in the study area according to the sample point distribution on the ground. The Sun positioning in February and October was similar 
in spite of having a difference in the Sun azimuth angle. Therefore, the sample points presented similar illumination classification at these two extreme dates when compared to the same classification in July, when the illumination classification changed in some sample points (colors represent the local illumination classification).

Figure 3. Examples of LISS-3 spectra and the canopy vertical profiles of some sample points under different local illumination conditions.

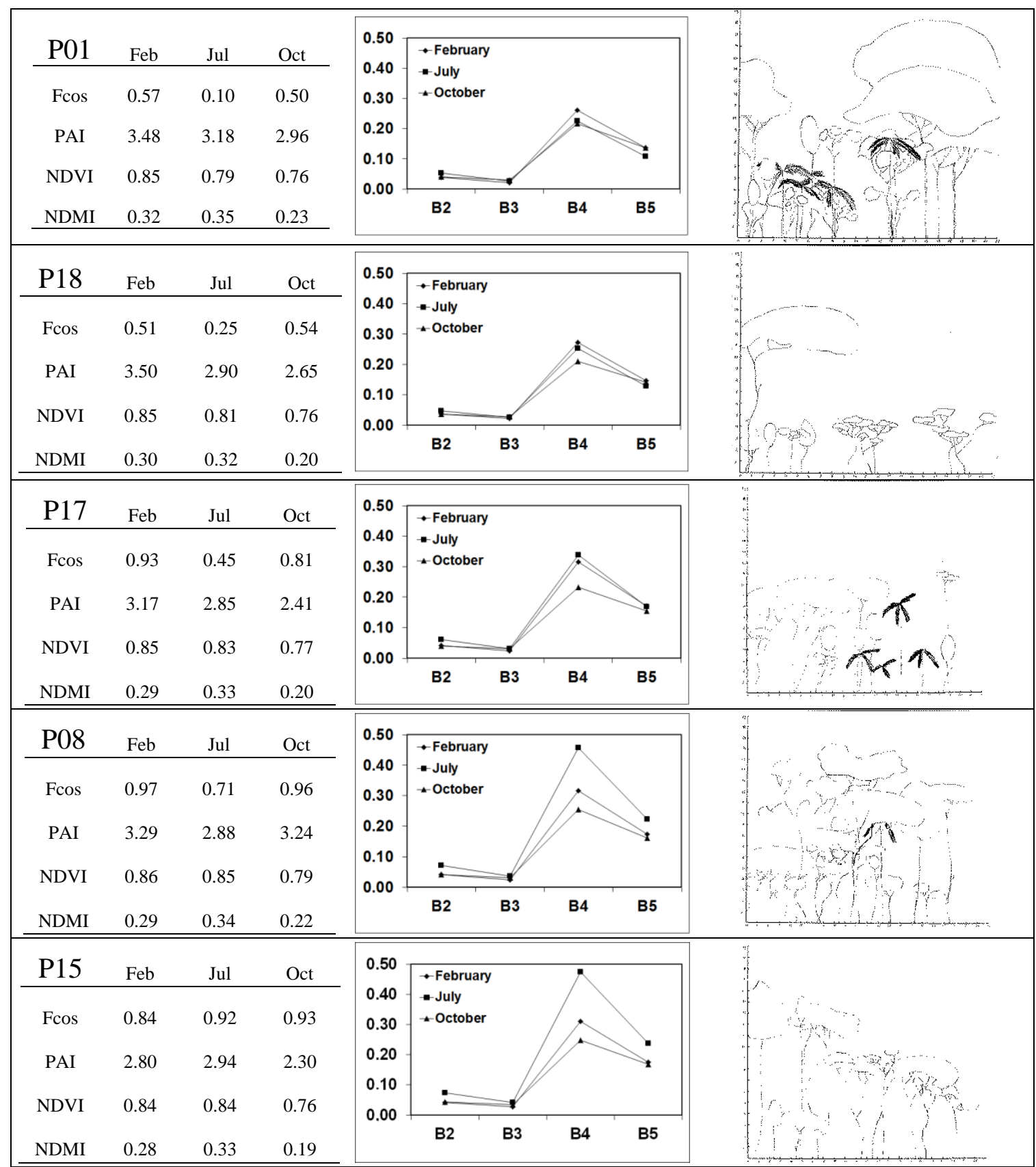

Vegetation cover can present some phenological variations from February to October mainly related to PAI changes. Such variations were evaluated through the use of hemispherical photography taken from the canopy ground in order to estimate PAI as carried out by [18]. Details of that procedure will be provided later. However, as the complete data collection was performed during 2012 and the forest 
fragment has been maintained as the forested preservation area, just local illumination changes and slight PAI variations were expected.

\subsection{Hemispherical Photography}

Hemispherical photography was adopted as an indirect method to estimate PAI. Therefore, at each sample point, 6 hemispherical photos were taken according to the strategy suggested by [28,29]. Each sample point was represented by a central point indicated by a wooden stack. The 6 hemispherical photos were taken around this central point, whose location was also materialized to enable taking photos during different campaigns exactly at the same point. The photos were taken at diffuse sky illumination (full of clouds) (either at dawn or at dusk) or quite early in the morning or quite late in the afternoon in an attempt to avoid direct Sun illumination.

The hemispherical photos were pre-processed based on two steps: (a) selecting the RGB channel that provided the best contrast between sky and vegetation; (b) the threshold definition for the PAI estimation. According to the remarks of [29], the blue channel (B) from the RGB composition frequently presents the best sky-vegetation contrast. Therefore, we opted for this channel. The threshold definition was based on a border detection method proposed by [30] that evaluates all digital number (DN) values (0-255) from the chosen RGB channel (in this case, Channel B). The threshold value is calculated based on the maximum distance between average values of DN from two groups or classes (sky and vegetation).

The next step was the hemispherical photos processing itself, which was carried out by the Gap Light Analyser 2.0 (GLA). The GLA setup was based on a view angle of $75^{\circ}$ from the zenith of the hemispherical photo, which defined a $150^{\circ}$ total viewing angle. The PAI of each one of the 30 sample points was estimated from the average PAI of the 6 subsamples.

\subsection{Vegetation Indices}

We decided to work with two vegetation indices based on red (R), near infrared (NIR) and shortwave infrared (SWIR):

Normalized Difference Vegetation Index (NDV),

$$
N D V I=\frac{\rho_{N I R}-\rho_{R}}{\rho_{N I R}+\rho_{R}}
$$

where: surface reflectance on near infrared; $\rho_{R}=$ surface reflectance on red; as originally proposed by [31].

Normalized Difference Moisture Index (NDMI),

$$
N D M I=\frac{\rho_{N I R}-\rho_{S W I R}}{\rho_{N I R}+\rho_{S W I R}}
$$

where: $\rho_{N I R}=$ surface reflectance on near infrared; $\rho_{S W I R}=$ surface reflectance on shortwave infrared. 


\subsection{Analysis Strategy}

The first step of the data analysis included a visual observation of the sample points spectra extracted from the orbital images and their vertical profiles, which have been built from the canopy structural data collected during the first field campaign performed in April.

Pearson correlation coefficients were calculated for PAI/Fcos and the radiometric variables (surface reflectance and vegetation indices) at each field campaign data set, and linear regression models were also built taking PAI as the independent variable and vegetation indices as the dependent ones. These linear regression models have been proposed just to illustrate the possible changes on vegetation indices and the biophysical variable (PAI) relationship using different data sets generated also at different local illumination conditions.

Considering the low phenological variation and the lack of manmade changes on the forest fragment, variation on the vegetation indices should be explained by local illumination rather than by biophysical variations.

\section{Results and Discussion}

Table 3 shows the PAI, Fcos, NDVI and NDMI average values for each sample point and field campaign with their respective standard deviation (SD).

According Table 3, in February, average PAI $=3.20$, NDVI $=0.853$, NDMI $=0.2984$, in July $\mathrm{PAI}=2.9, \mathrm{NDVI}=0.823, \mathrm{NDMI}=0.33$ and in October $\mathrm{PAI}=2.76, \mathrm{NDVI}=0.7627, \mathrm{NDMI}=0.2037$. Note that PAI and NDVI values decreased from the end of the wet season (February) toward the end of the dry season (October). The number of leaves decreased on the Atlantic Forest fragments, due to season variation in Brazil, which has been described by [20,21,23]. NDVI decreased as PAI also decreased, but NDMI increased from February to July and decreased from July to October. According to the NDMI formulation, if vegetation moisture increases, NDMI values should also increase, since the reflectance on SWIR spectral region decreases [32]. This apparent anomalous NDMI dynamic from February to July could be explained by the unusual precipitation level achieved in June in São José dos Campos. Actually, the forest moisture could have been higher in July than in February or the NDMI dynamic could also have been influenced by the local illumination that changed more from February to July than from February to October.

Note that SD values presented relative higher variation for Fcos through time with the highest SD value $=0.13$ confirming also the highest heterogeneous local illumination condition in July. PAI estimations are independent on local illumination, so it is expected that SD dynamic for that variable is more influenced by phenological variations. Vegetation indices are also influenced by local illumination, as mentioned by [33]. Here, SD values for the vegetation indices increased from February to July and presented similar values in October. Of course, these numerical results have been achieved from the 30 arbitrarily positioned sample points on the forest fragment utilized here. A different sample points positioning should change both the mean and standard deviation values.

Figure 3 shows Resourcesat/LISS-3 spectral profiles at the three dates and the canopy vertical profiles of some sample points. Here, just some data from sample points under different local illumination conditions have been shown assuming Fcos from July as a reference. 
Table 3. PAI, cosine factor (Fco), NDVI and NDMI for each sample point and field campaign.

\begin{tabular}{|c|c|c|c|c|c|c|c|c|c|c|c|c|}
\hline \multirow[b]{2}{*}{ Sample Point } & \multicolumn{4}{|c|}{ February } & \multicolumn{4}{|c|}{ July } & \multicolumn{4}{|c|}{ October } \\
\hline & PAI & Fcos & NDVI & NDMI & PAI & Fcos & NDVI & NDMI & PAI & Fcos & NDVI & NDMI \\
\hline 1 & 3.48 & 0.57 & 0.85 & 0.32 & 3.18 & 0.10 & 0.79 & 0.35 & 2.96 & 0.50 & 0.76 & 0.23 \\
\hline 2 & 3.62 & 0.92 & 0.86 & 0.30 & 3.13 & 0.64 & 0.83 & 0.36 & 2.90 & 0.91 & 0.77 & 0.20 \\
\hline 3 & 2.69 & 0.87 & 0.84 & 0.31 & 2.37 & 0.47 & 0.81 & 0.30 & 2.06 & 0.84 & 0.73 & 0.15 \\
\hline 4 & 2.89 & 0.73 & 0.84 & 0.30 & 2.54 & 0.51 & 0.82 & 0.32 & 2.44 & 0.74 & 0.77 & 0.20 \\
\hline 5 & 3.56 & 0.62 & 0.87 & 0.31 & 3.39 & 0.14 & 0.80 & 0.32 & 2.93 & 0.56 & 0.77 & 0.22 \\
\hline 6 & 3.31 & 0.71 & 0.85 & 0.31 & 2.95 & 0.35 & 0.80 & 0.35 & 2.84 & 0.70 & 0.76 & 0.21 \\
\hline 7 & 3.35 & 0.67 & 0.84 & 0.28 & 3.06 & 0.36 & 0.80 & 0.34 & 3.03 & 0.68 & 0.76 & 0.21 \\
\hline 8 & 3.29 & 0.98 & 0.86 & 0.29 & 2.88 & 0.71 & 0.85 & 0.34 & 3.24 & 0.96 & 0.79 & 0.22 \\
\hline 9 & 3.40 & 0.87 & 0.85 & 0.31 & 3.27 & 0.41 & 0.82 & 0.32 & 3.35 & 0.79 & 0.78 & 0.19 \\
\hline 10 & 2.62 & 0.87 & 0.85 & 0.29 & 2.40 & 0.76 & 0.85 & 0.34 & 2.38 & 0.92 & 0.78 & 0.22 \\
\hline 11 & 2.87 & 0.69 & 0.85 & 0.31 & 2.70 & 0.31 & 0.80 & 0.31 & 2.57 & 0.69 & 0.74 & 0.20 \\
\hline 12 & 3.83 & 0.71 & 0.87 & 0.31 & 3.48 & 0.27 & 0.84 & 0.34 & 3.40 & 0.65 & 0.76 & 0.22 \\
\hline 13 & 3.49 & 0.79 & 0.86 & 0.33 & 3.20 & 0.46 & 0.83 & 0.35 & 3.22 & 0.78 & 0.76 & 0.20 \\
\hline 14 & 3.12 & 0.60 & 0.84 & 0.30 & 3.07 & 0.28 & 0.80 & 0.33 & 2.78 & 0.62 & 0.75 & 0.20 \\
\hline 15 & 2.80 & 0.84 & 0.84 & 0.28 & 2.94 & 0.92 & 0.84 & 0.33 & 2.30 & 0.93 & 0.76 & 0.19 \\
\hline 16 & 3.43 & 0.95 & 0.84 & 0.28 & 3.06 & 0.86 & 0.85 & 0.35 & 2.77 & 0.99 & 0.78 & 0.21 \\
\hline 17 & 3.17 & 0.93 & 0.86 & 0.30 & 2.85 & 0.45 & 0.83 & 0.34 & 2.41 & 0.81 & 0.77 & 0.20 \\
\hline 18 & 3.50 & 0.52 & 0.85 & 0.30 & 2.91 & 0.25 & 0.81 & 0.33 & 2.65 & 0.55 & 0.76 & 0.20 \\
\hline 19 & 3.48 & 0.99 & 0.86 & 0.29 & 3.02 & 0.75 & 0.82 & 0.35 & 3.11 & 0.97 & 0.77 & 0.21 \\
\hline 20 & 3.19 & 0.87 & 0.87 & 0.31 & 2.87 & 0.53 & 0.84 & 0.36 & 3.21 & 0.85 & 0.78 & 0.24 \\
\hline 21 & 3.08 & 0.86 & 0.86 & 0.30 & 2.98 & 0.59 & 0.84 & 0.35 & 3.05 & 0.87 & 0.77 & 0.23 \\
\hline 22 & 3.62 & 0.86 & 0.86 & 0.30 & 3.17 & 0.59 & 0.85 & 0.33 & 3.19 & 0.87 & 0.78 & 0.21 \\
\hline 23 & 3.56 & 0.77 & 0.86 & 0.32 & 3.22 & 0.55 & 0.84 & 0.37 & 3.11 & 0.80 & 0.77 & 0.23 \\
\hline 24 & 3.36 & 0.64 & 0.84 & 0.29 & 3.30 & 0.05 & 0.79 & 0.30 & 3.25 & 0.52 & 0.76 & 0.22 \\
\hline 25 & 3.21 & 0.64 & 0.85 & 0.29 & 3.03 & 0.22 & 0.80 & 0.31 & 2.67 & 0.65 & 0.74 & 0.21 \\
\hline 26 & 3.00 & 0.84 & 0.84 & 0.28 & 2.71 & 0.58 & 0.83 & 0.31 & 2.30 & 0.85 & 0.75 & 0.19 \\
\hline 27 & 1.97 & 0.92 & 0.83 & 0.27 & 1.65 & 0.75 & 0.82 & 0.29 & 1.25 & 0.95 & 0.73 & 0.16 \\
\hline 28 & 3.70 & 0.95 & 0.86 & 0.30 & 3.49 & 0.63 & 0.85 & 0.34 & 3.52 & 0.92 & 0.78 & 0.21 \\
\hline 29 & 2.10 & 0.64 & 0.83 & 0.28 & 1.74 & 0.31 & 0.76 & 0.24 & 1.53 & 0.59 & 0.70 & 0.13 \\
\hline 30 & 3.25 & 0.89 & 0.87 & 0.28 & 2.56 & 0.80 & 0.86 & 0.34 & 2.27 & 0.94 & 0.78 & 0.20 \\
\hline Average & 3.20 & 0.79 & 0.85 & 0.30 & 2.90 & 0.49 & 0.82 & $\mathbf{0 . 3 3}$ & 2.76 & 0.78 & 0.76 & 0.20 \\
\hline SD & 0.55 & 0.07 & 0.01 & 0.02 & 0.50 & 0.13 & 0.02 & 0.03 & 0.68 & 0.08 & 0.02 & 0.02 \\
\hline
\end{tabular}

As mentioned before, no significant changes were expected at the canopy vertical structures from February to October. Therefore, we considered that the canopy vertical structure was the same during the satellite data collection in 2012. From the selected profiles shown in Figure 3, canopy structural differences are evident; however, these differences have not been described by the reflectance curves. Comparing data from sample Points 1 and 18, for instance (Figure 3), it is clear that the canopy at Point 1 was quite different from that at Point 18. Differences on the reflectance data from these two canopies would be expected, but the spectral curves were similar. It is clear that the spectral domain has been strongly influenced by factors other than canopy structure. Similar effects have been deeply 
discussed by [34] evaluating view-illumination effects on vegetation indices extracted from some Amazonian tropical forest canopies.

Spectral evaluations as the ones carried out here have also been performed by [35] when they studied variations in some Brazilian savanna physiognomies reflectance caused by seasonality and changes in viewing geometry using MISR/TERRA data. The authors explored significant vegetation cover phenological changes, which occurred in extreme seasonal data collection. Spectral changes were clear, since canopy structural variations were also significant. Of course, the effects of viewing geometry were also reported and clearly identified from MISR/TERRA data. In such a study, the authors were interested in evaluating the vegetation cover spectral characterization dynamics, as both phonological and acquisition geometry changed. Here, we have worked with no significant phenological changes, but with relative significant surface illumination variations.

The NIR spectral band (band 4) showed a stronger relationship with Fcos. Table 4 shows the Pearson correlation coefficients (r) estimated between PAI/Fcos and the radiometric variables at the three campaigns and from the 30 sample points. Similar results, but empirically relating forest above ground biomass (FAGB) with multi-angular CHRIS/PROBA data, have been reported by [3]. CHRIS is a hyperspectral orbital sensor whose objective is the collection of the Bidirectional Reflectance Distribution Function (BRDF) data from the Earth surface. It is the prime instrument of the PROBA-1 orbital platform. The authors described empirical relationships between FAGB and specific spectral bands data calculated from a single date multi-angular data set. They considered that there was no significant solar positioning variation during CHRIS/PROBA data acquisition. Therefore, according to the results achieved here, the empirical relationships should change if a different set of data were used (different local illumination condition).

Table 4. Pearson correlation coefficients (r) for PAI/Fcos and radiometric variables at the three campaigns.

\begin{tabular}{ccccccc}
\hline February & B2 & B3 & B4 & B5 & NDVI & NDMI \\
\hline PAI & -0.36 & -0.38 & 0.27 & 0.06 & 0.68 & 0.50 \\
Fcos & 0.60 & 0.53 & 0.76 & 0.82 & 0.23 & -0.28 \\
\hline July & B2 & B3 & B4 & B5 & NDVI & NDMI \\
\hline PAI & -0.35 & -0.25 & -0.04 & -0.18 & 0.22 & 0.59 \\
Fcos & 0.89 & 0.84 & 0.92 & 0.92 & 0.74 & 0.32 \\
\hline October & B2 & B3 & B4 & B5 & NDVI & NDMI \\
\hline PAI & -0.43 & -0.53 & 0.39 & -0.13 & 0.70 & 0.80 \\
Fcos & 0.44 & 0.39 & 0.72 & 0.81 & 0.34 & -0.04 \\
\hline
\end{tabular}

The relationships shown in Table 4 presented an interesting consistency between results from different campaigns with negative $r$-values for PAI $\times$ visible bands (B2 and B3), also a negative or weak relation between PAI and SWIR (B5), a positive relation for PAI $\times$ NIR (B4, just one exception in July) and a positive relation between PAI and both NDVI and NDMI. The stronger relationship between Fcos and the radiometric data, mainly with those calculated in July was evident. Note that r-values became higher in July when the local illumination changed as opposed to February and October. Therefore, the canopy spectral dynamics would be explained by the local illumination rather than by the canopy biophysical structural differences. 
PAI $\times$ vegetation indices relationships were higher than Fcos $\times$ vegetation indices just when there was a uniform local illumination condition (February and October). When the local illumination is not uniform, the vegetation indices dynamics seems to be explained by the local illumination rather than the biophysical parameters.

Figure 4 shows linear regression models that have been built with PAI, NDVI and NDMI data from the 30 sample points at each field campaign.

Figure 4. Linear regression models built with PAI, NDVI and NDMI from each sample point and at each field campaign.

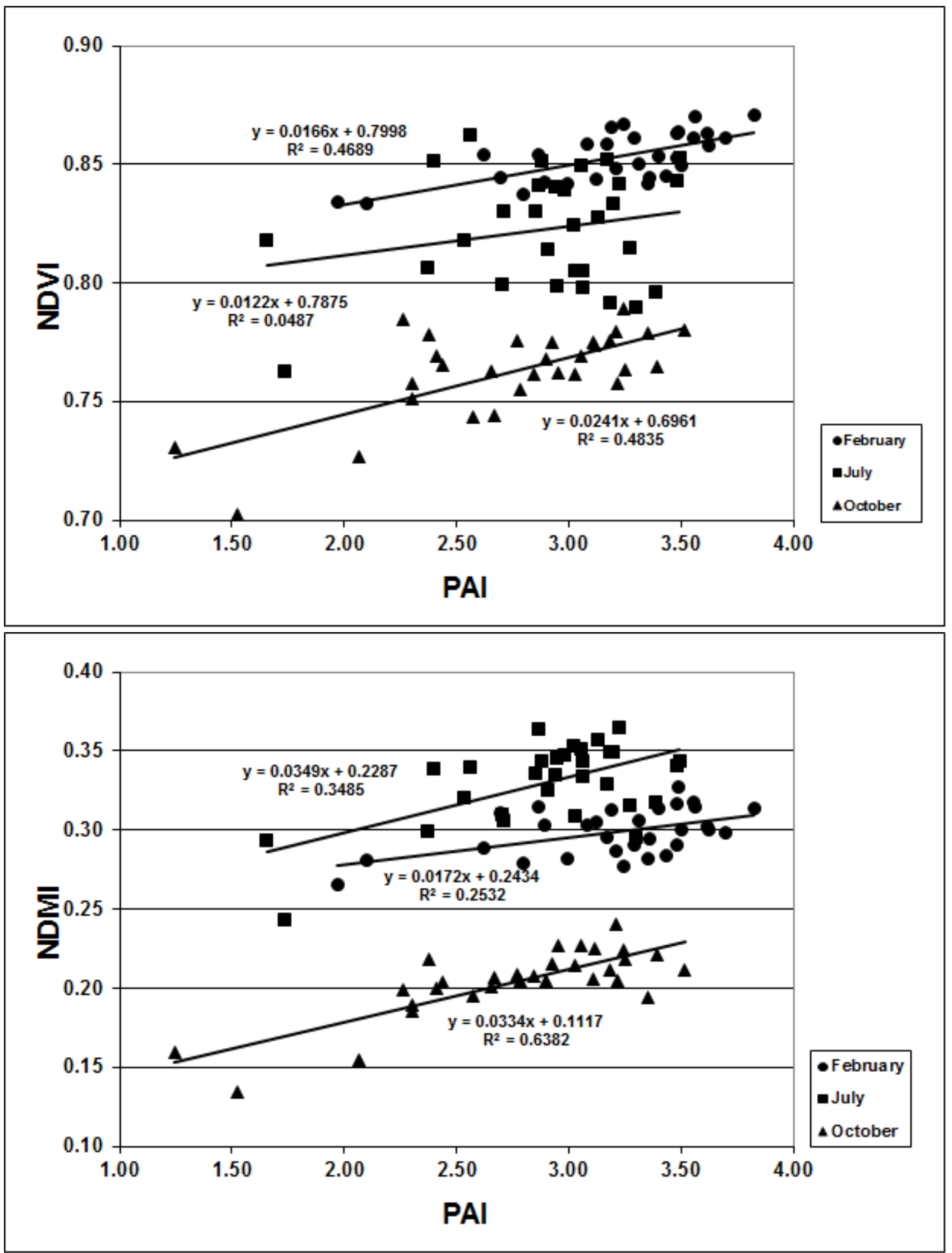


The linear regression models that have been proposed here assumed that the dependent variable is the vegetation indices, which are explained by a biophysical variable, in this case PAI.

From a superficial observation of the tendency lines for both NDVI and NDMI linear regression models, it is clear that the local illumination influences their relationships with PAI, since this variable presented low variation from February to October. The spectral behavior of the forest fragment was influenced by a sum of both topographic positioning and Sun positioning (local illumination) factors, which explains the vegetation indices dynamics rather than biophysical variations.

As mentioned before, these linear regression models have been proposed with an illustration propose, so they have not been utilized as vegetation index predictors using PAI as an independent variable.

\section{Conclusions}

This article was based on the assumption that empirical relationships between vegetation biophysical data and vegetation indices calculated from orbital radiometric data are influenced by the so-called "local illumination", which was defined here as a sum of data collection geometry (Sun and sensor positioning) and topographic conditions. Such an assumption has been neglected by several researchers exploring similar relationships.

The study area included a forest fragment dispersed on roughhouse topography, where 30 sample points were arbitrarily positioned, exploring the topographic diversity. Local illumination was expressed by the cosine factor (Fcos) that was calculated from topographic and solar position data at three different dates (February, July and October 2010). The Plant Area index (PAI) was estimated from each of the 30 sample points by hemispherical photography at the same time period (February, July and October 2010). Considering average values, in February PAI $=3.20$ (end of the wet season), in July PAI $=2.9$ (middle of the winter or dry season) and in October PAI $=2.76$ (the end of the dry season and the beginning of the wet season).

The Normalized Difference Vegetation Index (NDVI) and Normalized Difference Moisture Index (NDMI) were calculated from Resourcesat/Linear Imaging Self-Scanner 3 (Resourcesat/LISS-3) sensor data acquired at the same three opportunities mentioned above, considering also average values, in February NDVI $=0.853$ and NDMI $=0.2984$; in July NDVI $=0.823$ and NDMI $=0.33$ and in October NDVI $=0.7627$ and $\mathrm{NDMI}=0.2037$.

Empirical linear relationships between PAI/Fcos and Resourcesat/LISS-3 radiometric data, including NDVI and NDMI, were evaluated by the Pearson correlation coefficient ( $r$ ) at each date. The highest correlations were found between Fcos and the radiometric data at the three dates. Relationships between PAI and the vegetation indices were higher than Fcos $\times$ vegetation indices relationships when the majority of the sample points were well illuminated (February and October) or when there was uniform scene illumination (in February PAI $\times$ NDVI, $r=0.68$; PAI $\times$ NDMI, $r=0.50 ;$ Fcos $\times$ NDVI, $\mathrm{r}=0.23 ; \mathrm{F} \cos \times \mathrm{NDMI}, \mathrm{r}=-0.28$; in July PAI $\times$ NDVI, $\mathrm{r}=0.22 ; \mathrm{PAI} \times \mathrm{NDMI}, \mathrm{r}=0.59$; Fcos $\times$ NDVI, $r=0.74$; Fcos $\times$ NDMI, $r=0.32$ and in October PAI $\times$ NDVI, $r=0.70 ;$ PAI $\times$ NDMI, $r=0.80$; Fcos $\times$ NDVI, $r=0.34$; Fcos $\times$ NDMI, $r=-0.04$ ). When the local illumination was not uniform, the vegetation indices dynamics was explained by the local illumination rather than the biophysical parameters. 
According to the results presented here, future studies exploring empirical relationships between radiometric and vegetation biophysical data should take into account the local illumination influence on their results, mainly when working on roughhouse topography.

\section{Acknowledgments}

The authors would like to express their gratitude to the Conselho Nacional de Desenvolvimento Científico e Tecnológico (CNPq) for the financial support.

\section{Author Contributions}

Flávio Jorge Ponzoni wrote the paper and was intellectually responsible for the entire research. Clayton Borges da Silva was deeply involved in the field campaigns and data processing and analysis steps. This research was part of his Masters dissertation. Sandra Benfica dos was responsible for data organization and processing. Otávio Cristiano Montanher and Thiago Batista dos Santos participated in the field campaigns, helping in the definition and maintenance of the sample points.

\section{Conflicts of Interest}

The authors declare no conflicts of interest.

\section{References and Notes}

1. Jensen, J.R. Sensoriamento Remoto do Ambiente: Uma Perspectiva em Recursos Terrestres; Editora Parêntese: São José dos Campos, Brazil, 2011; p. 598.

2. Ponzoni, F.J.; Shimabukuro, Y.; Kuplich, T.M. Sensoriamento Remoto no Estudo da Vegetação, 2nd ed.; Editora Oficina de Textos: São Paulo, Brasil, 2012; p. 164.

3. Galvão, L.; Ponzoni, F.J.; Liesenberg, V.; Santos, J. Possibilities of discriminating tropical secondary succession in Amazônia using hyperspectral and multiangular CHRIS/PROBA data. ITC J. 2009, 1, 8-14.

4. Bhandari, S.; Phinn, S.; GILL, T. Assessing viewing and illumination geometry effects on the MODIS vegetation index (MOD13Q1) time series: Implications for monitoring phenology and disturbances in forest communities in Queensland, Australia. Int. J. Remote Sens. 2011, 32, 7513-7538.

5. Breuning, F.M.; Galvão, L.S.; Formaggio, A.R.; Epiphanio, J.C.N. Directional effects on NDVI and LAI retrievals from MODIS: A case study in Brazil with soybean. Int. J. Appl. Earth Obs. Geoinform. 2011, 13, 34-42.

6. Ponzoni, F.J.; Galvão, L.S.; Liesenberg, V.; SANTOS, J.R. Impact of multi-angular CHRIS/PROB data on their empirical relationships with tropical forest biomass. Int. J. Remote Sens. 2010, 31, 5257-5273.

7. Sims, D.A.; Rahman, A.F.; Vermote, E.F.; Jiang, Z. Seasonal and inter-annual variation in view angle effect effects on MODIS vegetation indices at three forest sites. Remote Sens. Environ. 2011, 115, 3112-3120. 
8. Verrelst, J.; Schaepman, M.E.; Koetz, B.; Kneubuehler, M. Angular sensitivity analysis of vegetation indices derived from CHRIS/PROBA data. Remote Sens. Environ. 2008, 112, 2341-2353.

9. Turner, D.P.; Cohen, W.B.; Kennedy, R.E.; Fassnacht, K.S.; Briggs, J.M. Relationships between leaf Area index and Landsat TM spectral vegetation indices across three temperate zone sites. Remote Sens. Environ. 1999, 70, 52-68.

10. Eklundh, L.; Harrie, L.; Kuusk, A. Investigating relationships between Landsat ETM+ sensor data and leaf area index in a boreal conifer forest. Remote Sens. Environ. 2001, 78, 239-251.

11. Wang, Q.; Adiku, S.; Tenhunen, J.; Granier, A. On the relationship of NDVI with leaf area index in a deciduous forest site. Remote Sens. Environ. 2005, 94, 244-255.

12. González-Sanpedro, M.C.; le Toan, T.; Moreno, J.; Kergoat, L.; Rubio, E. Seasonal variations of leaf area index of agricultural fields retrieved from Landsat data. Remote Sens. Environ. 2008, $112,810-824$.

13. Liu, J.; Pattey, E.; Jégo, G. Assessment of vegetation indices for regional crop green LAI estimation from Landsat images over multiple growing seasons. Remote Sens. Environ. 2012, 123, 347-358.

14. Laurent, V.C.E.; Schaepman, M.E.; Verhoef, W.; Weyermann, J.; Chávez, R.O. Bayesian object-based estimation of LAI and chlorophyll from a simulated Sentinel-2 top-of-atmosphere radiance image. Remote Sens. Environ. 2014, 140, 318-329.

15. Wohlfahrt, G.; Sapinsky, S.; Tappeiner, U.; Cernusca, A. Estimation of Plant Area Index of grasslands from measurements of canopy radiation profiles. Agric. For. Meteorol. 2001, 109, 1-12.

16. Holst, T.; Hauser, S.; Kirchgäßner, A.; Matzarakis, A.; Mayer, H.; Schindler, D. Measuring and modeling plant area index in beech stands. Int. J. Biometeorol. 2004, 48, 192-201.

17. Tracol, Y.; Gutiérrez, J.R.; Squeo, F.A. Plant area index and microclimate underneath shrub species from a Chilean semiarid community. J. Arid Environ. 2011, 75, 1-6.

18. Cantinho, R.Z. Avaliação de Proprziedades Biofísicas de Dosséis de Eucalyptus spp. Mediante Aplicação de Técnicas de Sensoriamento Remoto. Ph.D. Theis, Instituto Nacional de Pesquisas Espaciais, São José dos Campos, Brasil, 2012.

19. Silva, A.F. Composição Florística e Estrutura Fitossociológica do Estrato Arbóreo da Reserva Florestal Professor Augusto Ruschi, São José dos Campos, SP. Ph.D. Theies, Universidade Estadual de Campinas (UNICAMP), Campinas, Brazil, 1989.

20. Lemos Filho, J.P.; Mendonça Filho, C.V. Seasonal changes in the water status of three wood legumes from the Atlantic forest, Caratinga, Brazil. J. Trop. Ecol. 2000, 16, 21-32.

21. Pereira, T.S.; Costa, M.L.M.N.; Moraes, L.F.D.; Luchiari, C. Fenologia de espécies arbóreas em Floresta Atlântica da reserva biológica de Poço das Antas, Rio de Janeiro, Brasil. Iheringia Série Botânica 2008, 63, 329-339.

22. Morellato, L.P.C.; Talora, D.C.; Takahasi, A.; Benkle, C.C.; Romera, E.C.; Zipparro, W.B. Phenology of Atlantic rain forest trees: A comparative study. Biotropica 2000, 32, 811-823.

23. Oliveira Filho, A.; Fontes, M.A.I. Patterns of floristic differentiation among Atlantic forests in south-eastern Brazil, and the influence of climate. Biotropica 2000, 32, 793-810.

24. Markham, B.L.; Barker, J.L. Thematic mapper band pass solar exoatmospherical irradiances. Int. J. Remote Sens. 1987, 8, 517-523. 
25. Chander, G.; Markham, B.L.; Helder, D.L. Summary of current radiometric calibration coefficients for Landsat MSS, TM, ETM+ and EO-1 ALI sensors. Remote Sens. Environ. 2009, 113, 893-903.

26. Vermote, E.F.; Tanré, D.; Deuze, J.L.; Herman, M.; Morcrette, J.J. Second simulation of the satellite signal in the solar spectrum, 6S-An overview. IEEE Trans. Geosci. Remote Sens. 1997, 35, 675-686.

27. De Valeriano, M.M. Cálculo do Fator Topográfico de Iluminação Solar Para Modelagem Ecofisiológica a Partir do Processamento de Modelos Digitais de Elevação (MDE). In Proceedings of 2011 Simpósio Brasileiro de Sensoriamento Remoto, Curitiba, Brazil, 30 April-5 May 2011; pp. 5933-5940.

28. Jonckheere, I.; Flecks, S.; Nackaert, K. Review of methods for in situ leaf area index determination Part I. Theories, sensors and hemispherical photography. Agric. For. Meteorol. 2004, 121, 19-35.

29. Kearsley, E. Characterizing Spatial Variability of Tropical Rainforest Structure Using Hemispherical Photography, in the Reserves of Yangambi and Yoko (Democratic Republic of Congo). Master's Thesies, Universidade de Gante, Bruxelles, Belgium, 2011.

30. Nobis, M.; Hunziker, U. Autmatic thresolding for hemispherical canopy photographs based on edge detection. Agric. For. Meteorol. 2005, 128, 243-250.

31. Rouse, J.W., Jr. Monitoring the Vernal Advancement and Retrogradation (Green Wave Effect) of Natural Vegetation; NTIS No. E73-106393; Remote Sensing Center, Texas A\&M University: College Station, TX, USA, 1973.

32. Kumar, R. Radiation from Plants-Reflection and Emission: A Review; Research Project n:5543; Purdue Research Foundation: West Lafayette, IN, USA, 1974; p. 88.

33. Jackson, R.D.; Huete, A.R. Interpreting vegetation indices. Prev. Veterinary Med. 1991, 11, 185-200.

34. Galvão, L.S.; Breunig, F.M.; Santos, J.R.; dos, Moura, Y.M. View-illumination effects on hyperspectral vegetation indices in the Amazonian tropical forest. Int. J. Appl. Earth Obs. Geoinf. 2013, 21, 291-300.

35. Liesenberg, V.; Galvão, L.S.; Ponzoni, F.J. Variations in reflectance with seasonality and viewing geometry: Implications for classification of Brazilian savanna physiognomies with MISR/TERRA data. Remote Sens. Environ. 2007, 107, 276-286.

(C) 2014 by the authors; licensee MDPI, Basel, Switzerland. This article is an open access article distributed under the terms and conditions of the Creative Commons Attribution license (http://creativecommons.org/licenses/by/3.0/). 